Accelerator Development Department

$\mathrm{AD} / \mathrm{RHIC}-31$ BROOKHAVEN NATIONAL LABORATORY Associated Universities, Inc.

Upton, New York 11973

RHIC TECHNICAL Note No. 31

\title{
RHIC PERFORMANCE LIMITATIONS DUE TO BEAM HEATING \\ OF VACUUM CHAMBER
}

\author{
H. Hahn
}

December 31, 1987 


\section{RHIC Performance Limitations Due to Beam Heating \\ of Vacuum Chamber}

H. Hahn

\section{Introduction}

Beam heating due to the wall resistance has been the reason for requiring copper-plated cold-bore vacuum chambers in the SSC and HERA magnets. The Conceptual Design Report of RHIC, in contrast, assumes a stainless steel vacuum chamber. Estimates of the resistive wall heating indicated that stainless steel beam tubes are adequate, with considerable margin, for the nominal RHIC design numbers. However, the desire to provide room for future performance upgrades, in particular higher luminosities and shorter bunches, requires a review of the choice regarding stainless/copper-plated beam tubes. Whereas most other technical components allow modification without great financial penalties, the beam tube of a superconducting magnet system is quasi-permanent. In this note, an estimate of the limitations on beam intensity (and consequently luminosity) due to beam heating of stainless steel vacuum chambers are presented.

\section{Wall Heating Estimates}

Estimates of the resistive wall heating are obtained from the expression given in Appendix I. The power per unit length of the beam tube depends on beam and beam tube parameters according to the scaling 1 aw ${ }^{1,2,3}$

$$
P^{\prime} \propto \frac{M\left(N_{B} Q\right)^{2}}{b R \sigma_{\ell}^{3 / 2} \sigma^{1 / 2}}
$$

${ }^{1}$ A. Piwinski, DESY Report DESY 72/72 (1972).

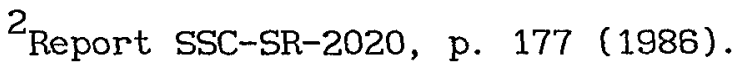

${ }^{3}$ A. G. Ruggiero, BNL Report AD/RHIC-AP-48 (1987). 
where

$$
\begin{aligned}
& \mathrm{R}=\text { machine radius } \\
& \mathrm{b}=\text { vacuum chamber radius } \\
& \mathrm{M}=\text { number of bunches/ring } \\
& \mathrm{N}_{\mathrm{B}}=\text { number of } \text { ions/bunch } \\
& \sigma_{\ell}=\text { rms bunch length } \\
& \sigma=\text { wall conductivity } \\
& \mathrm{Q}=\text { charge of ion } \\
& Z_{0}=c \mu_{0}
\end{aligned}
$$

The rms bunch length is related to the bunch area in longitudinal phase space and the $\mathrm{rf}$ parameters as shown in Appendix II. The bunch area is determined by the injector $(S=0.3 \mathrm{eV} \cdot \mathrm{sec} / \mathrm{u}$ for $\mathrm{Au}$ and $1 \mathrm{eV} \cdot \mathrm{sec}$ for $\mathrm{p}$ beams). The desire to operate with smallest diamond length makes it imperative to retain the injector bunch area during the injection and acceleration phases and avoid manipulations which would lengthen the bunch and reduce wall heating.

Estimates of the coil temperature increase in dipole magnets due to resistive wall heating have been made by Shutt and Wu. ${ }^{4}$ The estimated steady-state temperature rise of the coil end where the helium exits is about $0.04 \mathrm{~K} / \mathrm{W}$ and the resulting reduction of the quench field is about $0.9 \mathrm{~T} / \mathrm{W}^{5}$ Heat generated in the beam tube is assumed to be removed mostly by the helium flowing in the coil passages with only negligible heat being conducted through the iron yoke into the helium bypass. A further approximation is made by neglecting the heat capacity of the coil compared to the helium in the coil. Ignoring the axial extent of the coil, the temperature rise of the coil is then given by

where

$$
\frac{\mathrm{d} \theta}{\mathrm{d} t}+\frac{\dot{\mathrm{m}}}{\mathrm{m}} \theta=\frac{\mathrm{P}_{\mathrm{d}}}{\mathrm{C} \mathrm{m}}
$$

$P_{d}=$ wall heating/dipole

$\mathrm{m}=$ stored helium mass in coil $(\sim 400 \mathrm{~g})$

$\dot{\mathrm{m}}=$ helium flow in coil $(7-8 \mathrm{~g} / \mathrm{sec})$

$\mathrm{C}=$ specific heat of supercritical He at $4.5 \mathrm{~K}$ and 5 atm $\left(3.5 \mathrm{Jg}^{-1} \mathrm{~K}^{-1}\right.$ )

${ }^{4}$ K. C. Wu, private communication (1987).

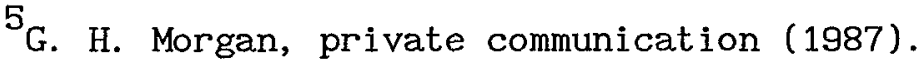


The time constant with which the steady state temperature is reached follows from

$$
\tau_{\theta}=\mathrm{m} / \dot{\mathrm{m}}
$$

to be about $1 \mathrm{~min}$. Heating of the coil is a relatively fast process when compared to the total beam storage time but it must be compared to bunch length growth by beam diffusion, in particular due to intrabeam scattering, in order to determine if these temperatures are actually reached.

The diffusion rates due to intrabeam scattering are above the transition energy given by the approximate formulae ${ }^{6}$

$$
\tau_{E}^{-1}=\frac{1}{\delta_{E}} \frac{d \delta_{E}}{d t}=\left[\frac{\left\langle\sigma_{H}\right\rangle}{\left\langle X_{p}\right\rangle \delta_{E}}\right]^{2} \tau_{H}^{-1}
$$

with

$$
\tau_{H}^{-1}=\frac{27 \pi}{2} L_{g} r_{p}^{2} E_{o} \frac{N_{B}}{S \varepsilon_{H} \varepsilon_{V}} \frac{\left\langle X_{p}\right\rangle}{\langle\beta\rangle} \frac{1}{\left(1+\left[\frac{\left\langle\sigma_{H}\right\rangle}{\left\langle X_{p}\right\rangle \delta_{E}}\right]^{2}\right]^{1 / 2}}\left[\frac{Q^{2}}{A}\right]^{2}
$$

where

$$
\begin{aligned}
L_{g} & \approx 20 \\
r_{p} & =\frac{\mu_{0} e^{2} c^{2}}{4 \pi E_{O}} \\
\left\langle\sigma_{H}\right\rangle & =\left[\frac{\varepsilon_{H}}{6 \pi} \frac{\langle\beta\rangle}{\gamma}\right]^{1 / 2} \\
\varepsilon_{H, V} & =\text { bunch area } \\
\left\langle X_{p}>\right. & =\text { averaged dispersion } \\
\langle\beta\rangle & =\text { averaged betatron function }
\end{aligned}
$$

${ }^{6}$ G. Parzen, Nucl. Instr. Methods, A256, p. 231 (1987). 
The initial diffusion times are at top energy $\tau_{E}>160 \mathrm{~min}$ for protons ( $\varepsilon=20 \pi \times 10^{-6} \mathrm{~m}$ ) and $\tau_{E}>1 \mathrm{~min}$ for gold $\left(\varepsilon=10 \pi \times 10^{-6} \mathrm{~m}\right)$. It follows that in the case of proton beams, the temperature increases at a faster rate than the resistive heating decreases due to bunch lengthening from intrabeam scattering. In the case of high-intensity gold beams $(2-3 \times$ CDR values), heating and bunch lengthening have comparable time constants, and the temperature rise of the coil is likely to be smaller than calculated. However, if intrabeam scattering is counteracted by stochastic cooling, full heating of the dipole coil is to be expected.

\section{Intensity and Luminosity Limitations}

The wall heating estimates for various gold and proton operation conditions are given in Tables I and II. Also shown is the maximum number of ions per bunch assuming a $2 \mathrm{~W} /$ dipole wall heating limit. Although no hard limit on the tolerable wall heating exists, it would seem that this value is acceptable. A wall heating of $2 \mathrm{~W} /$ dipole has to be compared with the total $3.5 \mathrm{~W} /$ dipole heat load allowance due to other sources. It is to be noted that heating of the beam tube (as well as beam radiation) is likely to increase the coil temperature directly whereas all other heat loads have only a broad impact on the cryogenic system.

The nominal design beam intensities are initial1y, i.e., without diffusion due to intrabeam scattering, at the beam-beam limit given by a tuneshift of $v_{B B} \approx 3 \times 10^{-3}$. At higher intensities, the luminosity in the beam-beam limit is given by

$$
L_{B B}=\frac{c}{2 \pi r_{p}} \frac{\gamma M N_{B}}{R} \frac{A}{Q^{2}} \frac{\Delta v_{B B}}{\beta^{*}}
$$

The estimated limits on luminosity due to resistive wall heating are given in Tables $I$ and II.

Resistive heating of a copper-plated beam tube is reduced by a factor of about $30\left(\sigma_{\mathrm{Cu}}=1.8 \times 10^{9} / \Omega \mathrm{m}\right.$ versus $\left.\sigma_{\text {ss }}=2 \times 10^{6} / \Omega \mathrm{m}\right)$ and thus for all practical considerations negligible. The skin depth at the bunch frequency $(M=57)$

$$
f_{B}=\frac{c M}{2 \pi R}=4.46 \mathrm{MHz}
$$


follows to be

$$
\delta=\left(\mu_{\mathrm{O}} \pi f_{B} \sigma\right)^{-1 / 2}=5.6 \mu \mathrm{m}
$$

A $12-24 \mu \mathrm{m}(0.5-1 \mathrm{mil})$ thick copperplating would thus seem sufficient to eliminate wall heating. Stresses and deflections during quenches in RHIC dipoles were calculated by Shutt ${ }^{7}$ who concluded that $1 \mathrm{mil}$ plating is acceptable.

In summary, copperplating of the beam tube is recommended in order not to limit future RHIC performance improvements. The possibility of copperplating requires additional R\&D efforts and it will increase construction cost. An acceptable compromise to minimize cost would be to copperplate dipole beam tubes only. Quadrupoles without copperplating may also be advantageous for the fast gamma-transition jump.

${ }^{7}$ R. P. Shutt, BNL Report RHIC-MD-63 (1987) 
TABLE I. Wall Heating in RHIC (Gold operation)

\begin{tabular}{|c|c|c|c|c|c|c|}
\hline & Nominal & Design & \multicolumn{4}{|c|}{ Wall Heat Limits } \\
\hline Energy, $E$ & 11.6 & 100 & 100 & 100 & 100 & $\mathrm{GeV} / \mathrm{u}$ \\
\hline \# ions/bunch, $\mathrm{N}_{\mathrm{B}}$ & 1.2 & 1.1 & 4 & 2.4 & 2.2 & $\times 10^{9}$ \\
\hline Harmonic, $h$ & 342 & 342 & 342 & 342 & 684 & \\
\hline rf voltage, $v$ & 0.21 & 1.2 & 1.2 & 2.4 & 2.4 & MV \\
\hline Bunch area, S & 0.3 & 0.3 & 0.3 & 0.3 & 0.3 & $\mathrm{eV} \cdot \mathrm{sec} / \mathrm{u}$ \\
\hline rms bunch length, $\sigma_{\ell}$ & 0.99 & 0.27 & 0.27 & 0.22 & 0.19 & $\mathrm{~m}$ \\
\hline Peak current, $\mathrm{I}_{\mathrm{p}}$ & 1.68 & 6.18 & 22.4 & 15.7 & 17.5 & A \\
\hline \# bunches, $\mathrm{M}$ & 57 & 57 & 57 & 114 & 114 & $:$ \\
\hline Wallheat/dipole@ss & 0.02 & 0.15 & 2.0 & 2.0 & 2.0 & W \\
\hline Wallheat/dipole @ $\mathrm{Cu}$ & 0.7 & 0.5 & 67 & 66 & 69 & $\mathrm{~mW}$ \\
\hline Intrabeam scattering $\tau_{\mathrm{E}}$ & & 2.1 & 0.5 & 1.1 & 1.5 & $\min$ \\
\hline Maximum Luminosity, $L_{B B}$ & & 1.1 & 3.9 & 4.7 & $4.3 \times 10^{2}$ & ${ }^{7} \mathrm{~cm}^{-2} \sec ^{-1}$ \\
\hline
\end{tabular}


TABLE II. Wall Heating in RHIC (proton operation)

\begin{tabular}{|c|c|c|c|c|c|c|}
\hline & \multicolumn{2}{|c|}{ Nominal Design } & \multicolumn{4}{|c|}{ Wall Heat Limits } \\
\hline Energy, E & 29.5 & 250 & 250 & 250 & 250 & $\mathrm{GeV}$ \\
\hline \# ions/bunch, $\mathrm{N}_{\mathrm{B}}$ & 1.0 & 1.0 & 3.5 & 2.2 & 2.0 & $\times 10^{11}$ \\
\hline Harmonic, $\mathrm{h}$ & 342 & 342 & 342 & 342 & 684 & \\
\hline rf voltage, $V$ & 0.0165 & 1.2 & 1.2 & 2.4 & 2.4 & MV \\
\hline Bunch area, $\mathrm{S}$ & 1.0 & 1.0 & 1.0 & 1.0 & 1.0 & $\mathrm{eV} \cdot \mathrm{sec}$ \\
\hline rms bunch length, $\sigma_{\ell}$ & 1.32 & 0.31 & 0.31 & 0.26 & 0.23 & $\mathrm{~m}$ \\
\hline Peak current, $I_{p}$ & 1.45 & 6.18 & 21.6 & 16.2 & 16.7 & A \\
\hline \# bunches, M & 57 & 57 & 57 & 114 & 114 & \\
\hline Wallheat/dipole @ ss & 0.02 & 0.16 & 2 & 2 & 2 & W \\
\hline Wallheat/dipole @ Cu & 0.6 & 5.4 & 67 & 68 & 68 & $\mathrm{~mW}$ \\
\hline Intrabeam scattering $\tau_{E}$ & & 410 & 110 & 220 & 290 & $\min$ \\
\hline Maximum Luminosity, $L_{B B}$ & & 0.8 & 2.7 & 3.4 & $3.1 \times 10^{3}$ & ${ }^{1} \mathrm{~cm}^{-2} \mathrm{sec}^{-1}$ \\
\hline
\end{tabular}




\section{APPENDIX I. RESISTIVE WALL HEATING}

RESISTIVE WALL HEATING PER RING

$$
P=\frac{\Gamma(3 / 4)}{2 \pi} \quad \frac{M}{b} I_{p}^{2} \quad\left[\frac{Z_{o} \sigma_{\ell}}{2 \sigma}\right]^{1 / 2}
$$

WALL HEATING PER UNIT LENGTH

$$
\mathrm{P}^{\prime}=\frac{\Gamma(3 / 4)}{2 \pi}\left[\frac{\mathrm{M} \sigma_{\ell}}{\mathrm{R}}\right]^{1 / 2} \mathrm{R}_{\mathrm{M}} \mathrm{I}_{\mathrm{p}}^{2}
$$

WITH PEAK CURRENT

$$
I_{P}=\frac{e c}{(2 \pi)^{1 / 2}} \frac{Q N_{B}}{\sigma_{\ell}}
$$

WALL RESISTANCE PER UNIT LENGTH

$$
R_{M}=\frac{1}{2 \pi b}\left[\frac{Z_{o} M}{2 \sigma R}\right]^{1 / 2}
$$

AND

$$
\begin{aligned}
& \mathrm{R}=\text { machine radius } \\
& \mathrm{b}=\text { vacuum chamber radius } \\
& \mathrm{M}=\text { number of bunches/ring } \\
& \mathrm{N}_{\mathrm{B}}=\text { number of } \text { ions/bunch } \\
& \sigma_{\ell}=\text { rms bunch length } \\
& \sigma=\text { wall conductivity } \\
& \mathrm{Q}=\text { charge of ion. } \\
& \mathrm{Z}_{0}=\text { c } \mu_{0}
\end{aligned}
$$


APPENDIX II. RF BUCKET AND LONGITUDINAL BUNCH PARAMETERS

BUCKET HALF HEIGHT

$$
\Delta_{B}=\left[\frac{2 e v}{\pi h|\eta| \gamma E_{\mathrm{O}}} \frac{\mathrm{Q}}{\mathrm{A}}\right]^{1 / 2}
$$

BUCKET AREA/AMU

$$
A_{B}=8 \Delta_{B} \frac{\gamma E_{o}}{\bar{h} \omega_{O}}
$$

BUNCH PHASE HALF WIDTH $0<\phi<\pi$

COLE-MORTON:

$$
N=\sin ^{2} \phi / 2
$$

RMS BUNCH LENGTH

$$
\sigma_{\ell}=\frac{1}{\sqrt{6}} \quad \frac{\mathrm{R}}{\mathrm{h}} \phi
$$

RMS BUNCH HEIGHT

$$
\delta_{E}=\frac{1}{\sqrt{6}} \Delta_{B} \sin \phi / 2
$$

BUNCH AREA/AMU

$$
S=A_{B}\{(N-1) K(N)+E(N)\}
$$

$$
\approx 6 \pi \sigma_{\ell} \delta_{E} \gamma E_{o} / c
$$

